\section{Fresh funding offers lifeline to bioinformatics centre}

Declan Butler, Paris and Alison Abbott, Munich The European Bioinformatics Institute (EBI) based near Cambridge in Britain is to receive an infusion of 19 million euros (US\$16.6 million) from the European Commission over the next three years.

The cash injection marks an important turning point for the EBI. In 1999, the institute faced bankruptcy after the European council of research ministers decided that the fifth Framework funding programme would not support core funding and operational costs for infrastructure.

But after widespread protests, the European Commission effectively reversed this decision last November and earmarked 25 million euros over three years for "genomic and proteomic databases and repositories of suitable animal models".

Programmes coordinated by the EBI will receive the lion's share of this sum. Among the non-EBI projects to benefit is the European Mouse Mutant Archive (EMMA), centred in Rome, which will get 4 million euros. "This has been a real life-saver for us," says Martin Hrabé de Angelis, EMMA's scientific director.

Of the total grant to the EBI, 4.3 million euros each year will go directly to the institute for its own operations, adding to existing support of 8.4 million euros per year from the European Molecular Biology Labo-

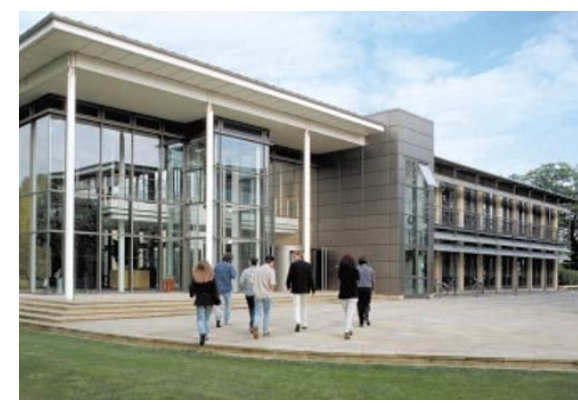

On the up: the European Bioinformatics

Institute is benefiting from an injection of cash.

ratory - set to increase to 11.4 million euros by 2005 - and annual funding of around 2 million euros from the Wellcome Trust.

A new plan to integrate biological databases, known as Integr8, is the largest single project to be supported with the funds. This will develop standards, databases and software to allow scientists to draw on relevant material from all biological databases and the scientific literature. "This is perhaps the project I'm most excited about," says Graham Cameron, joint head of the EBI.

In addition, 6 million euros will be spent implementing a planned European Macromolecular Structure Database. This is intended to serve as a counterpart to the US Protein Data Bank.
Physicists put a value that matters on the standard model

Josette Chen

Experimental physicists have derived a more definitive value for the parameter that explains the surplus of matter over antimatter when the Universe began. But the result has left theorists with some explaining to do.

At a 10 May seminar at CERN, the European Laboratory for Particle Physics in Geneva, the researchers announced that they had obtained measurements that further confirmed the existence of 'charge-parity (CP) violation' - the phenomenon predicted by the standard model of particle physics to be behind the existence of matter in the Universe.

The CERN team reported a value of $15.3 \pm 2.6 \times 10^{-4}$ for the parameter linked to CP violation. "These errors are considerably smaller than any reported before," says Frank Wilczek, a theoretical physicist from the Massachusetts Institute of Technology.

But theoretical calculations forecast a larger range of values for the parameter of between $4.2 \times 10^{-4}$ and $13.7 \times 10^{-4}$ (see Nature 402, 22-23; 1999). "It is hard to say whether these new results are consistent with the standard model," Wilczek says. "The torch has now been passed on to the theoretical side."

\title{
Resuscitated 'alien' microbes stir up an Italian storm
}

\section{Alison Abbott}

Two Naples scientists claim to have found extraterrestrial bacteria in ancient rocks and meteorites from one of the city's museums. Italy's national academy of sciences, the Accademia dei Lincei, agreed to publish the controversial result after a heated debate on 11 May.

Bruno D'Argenio, a geologist and academy member, and Giuseppe Geraci, a molecular biologist, told the academy's general meeting in Rome that they had brought back to life dried up bacteria, which they believe had been locked up in the rocks for millions of years.

The scientists say they did this by simply adding culture medium to samples of the rock and meteorite placed on glass slides. They argue that their techniques exclude the possibility of contamination, and claim that the results prove that life exists, and perhaps even evolved, in outer space.

But most biologists at the meeting were unconvinced that contamination could be ruled out. And they said they were concerned that the authors had bypassed peer review by presenting their findings directly to the academy.

The sceptics were also angry that the scientists had announced their results at a
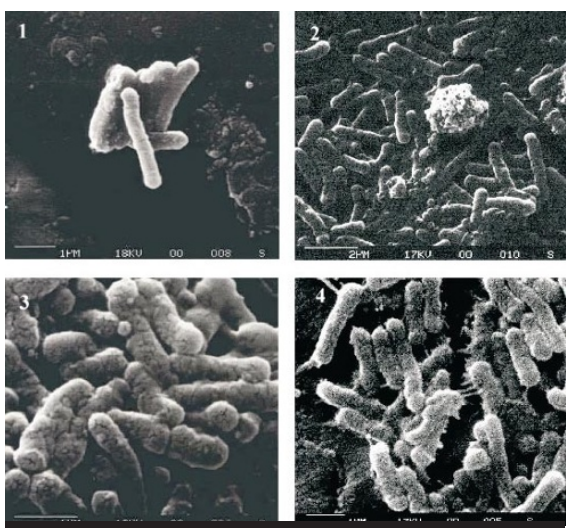

Back to life: the reconstituted bacteria that are claimed to be ancient extraterrestrials. press conference two days before the academy meeting. D'Argenio and Geraci won widespread media coverage in Italy and abroad after they showed journalists a movie of the reconstituted bacteria swimming.

According to Mario Stefanini, a cell biologist at the University of Rome, academy rules allow members to present their data to the academy, and then to publish them as part of the academy's proceedings. The academy president, mathematician Edoardo Vesentini, ruled that in this case the paper should be accompanied by a transcript of the debate.

Russell Vreeland of West Chester University in Pennsylvania says experts in the field know how difficult it is to avoid contamination in such research, and that "this is why peer review is so important".

Tom Shepherd of the British Geological Survey at the University of Leicester concurs, saying of the results: "The community is cautious, and quite rightly so."

i www.cryms.org 